\title{
Refresh Memory: Chinese Ceramics Goes to the World - the Ceramic Conversation among Chinese IAC Members
}

\author{
Zhang Ganlin ${ }^{1, a,{ }^{*}}$, Yu Qin ${ }^{1, b}$ and Feng Mingyan ${ }^{1, c}$ \\ 1 Jingdezhen Ceramic Institute, Jingdezhen, Jiangxi, China \\ azhangganlin@jci.edu.cn, b454973884@qq.com, c1538824791@qq.com \\ *Zhang Ganlin
}

Keywords: IAC, Contemporary ceramic art, International discourse right, Inheritance and innovation.

\begin{abstract}
As the only international organization that represents ceramic academic field in UNESCO, the International Academy of Ceramics (IAC) has developed in China within more than 10 years. But in such a short period, with the participation and effort of Chinese IAC members, the Chinese contemporary ceramic art has gradually taken its role on this platform in the international community. This tour exhibition of the works and documents of Chinese IAC members is their presentation to the ceramic field. From these works, we can not only see the traditional Chinese inheritance and innovation of contemporary ceramic art, but also feel their efforts to promote the Chinese ceramics going to the world.
\end{abstract}

\author{
士别三日: 中国陶瓷走向世界 \\ 一一国际陶艺学会（IAC）中国会员的陶艺对话 \\ 张甘霖 $1, a, *$, 余沁 ${ }^{1, b}$, 冯明燕 $1, c$ \\ 1 景德镇陶瓷大学, 景德镇, 江西, 中国 \\ azhangganlin@jci.edu.cn, b454973884@qq.com, c1538824791@qq.com \\ *张甘霖
}

关键词: IAC; 当代陶艺; 国际话语权; 继承与创新

中文摘要. 作为联合国教科文组织框架下在陶瓷媒介领域里唯一代表国际陶瓷学术领域高度 的一个组织, 国际陶艺学会 (IAC) 在中国的发展仅有十多年的历史。但是在如此短的时间 里, 随着一批又一批中国会员的加入和努力, 借助这个平台, 中国当代陶艺在国际上逐渐发 声。这场展览是IAC中国会员的作品与文献巡回展, 是他们向陶艺界同仁展示他们努力成果 的汇报。从这些作品中, 我们不仅能看到当代陶艺对于中国传统的继承与创新, 而且能感受 到他们为推动中国陶瓷走向世界所作出的努力。

\section{1. 引言}

古人云：士别三日，当刮目相看。意为 “消除成见，更新认知”。很多年前，日本作为 国际陶艺学会 (以下简称IAC) 会员大国, 一直在无形中让西方学者和艺术家误以为陶瓷始 于日本, 这是一种与历史相违背的认知。但随着1999年秦锡麟与陈淞贤老师成为IAC的第一 
批中国会员, 2008年第43届国际陶艺会员大会于西安召开, 中国当代陶艺家们正在依托IAC 这一平台积极参与国际文化交流活动, 更新世界对于中国陶艺的认知, 并逐渐在国际上发声。 士别三日这场展览正是一次IAC中国会员作品与文献的展示, 旨在通过丰富多彩的作品与陶 艺界同仁交流自己的创作理念。这不仅是一次成果的汇报、一个多元化当代陶艺的缩影，更 是一次思想的碰撞, 意欲在交流学习中, 共同探讨如何在IAC这个国际陶艺组织框架下将中 国陶瓷更好地推动走向世界，拥有更多属于中国文化自己的国际话语权。

\section{2. 展览主题一一东西方陶艺文化的交流和融合}

整个展览由开幕式、研讨会及作品文献展览三部分组成。开幕式上，IAC中国区理事周 光真先生、著名陶艺家周国桢教授、景德镇陶瓷大学副校长宁钢教授、中国艺术研究院文化 艺术创作院院长朱乐耕教授等专家学者就IAC在中国的发展历程、这场展览的宗旨、东西方 陶艺文化的交流和融合以及观展后人们应观照自身做出反思进行了阐述, 并发表了自身对于 中国陶瓷未来如何与世界对话的看法。

二十世纪八十年代中期, 随着八五思潮的兴起, 中国艺术家们开始争相学习、摹仿西方 现代艺术，更有甚者为了追求西方的形式主义而抛弃自身的文化自觉，即舍弃中国自己的传 统文化, 这让人不由感叹, “老八股还没赶走, 又来了个新八股”。他们以西方的价值体系 进行艺术创作，尽管 “新的洋框框还显得很粗野、缺乏修养”，与中国本土的语言、审美、 文化价值体系并不相符合，但他们仍然期待自己 “孤注一掷” 的作品能在世界艺术中占有一 席之地。当这股浪潮经过时间的沉淀, 人们开始意识到世界多元化、文化多样性。正如朱乐 耕教授在开幕式上所说, 这是一个地球村的时代, 我们要在拥有国际化眼光的同时注重本土 文化发展。自古以来，人与人之间就存在交流，交流促进文化的发展，若都是千篇一律，那 么生活将索然无味。而这场展览很好的印证了文化多元的存在, 因为会员所展出的作品既有 体现工匠精神、追求精致完美的实用器血, 又有展示窑火与釉色变幻莫测的裸烧工艺; 既有 雕塑类陶艺作品, 又有占据一定空间的装置艺术; 既有工业设计类陶瓷产品, 又有追寻开拓 精神的观念艺术。正是这些以陶瓷为媒介、将中国传统文化传承与创新的作品, 让世界对中 国陶瓷消除成见、更新认知。且一如IAC中国区理事周光真先生所说: “这不仅是一种需要, 也是一种习惯。

除了开幕式上几位专家学者的发言，研讨会上每一位参展的IAC中国个人会员均通过幻 灯片介绍了自己的艺术与创作经历，团体会员则向大家展示了他们的院校/社团机构的背景和 国际陶艺交流情况。深圳雕塑院副院长夏和兴对于该研讨会给予了高度评价, 称它有效地将 这场展览进行了深入继续探究, 让观众无论是对参展艺术家还是IAC这个国际陶艺组织, 都 有了更深层的了解。

\section{3. 研讨会一一中国陶艺的继承发扬、国际话语权和文化多样性}

这场研讨会是一次艺术家与艺术家、艺术家与理论家、传统与现代的思想碰撞。期间， 穿插于IAC中国会员的自身介绍中, 有几个问题被反复聚焦: 中国陶艺的继承发扬、国际话 语权和文化多样性等问题。

著名陶艺家周国桢教授在开幕式和研讨会上再三发问：什么是属于我们中国的现代陶 艺? 众所周知, 随着现代绘画艺术的兴盛和人们对于禅宗的理解, 以八木一夫为首的日本走 泥社和以彼得 - 沃克斯为代表发起的奥蒂斯革命突破 “容器主义” 的桎梏, 开启了全新的陶 艺时代。20世纪八十年代, 中国这片土地也迎来了以现代主义审美为特征的美术新思潮。但 是在学习西方现代艺术的转型过程中, 一部分艺术家慢慢偏离了艺术的本质, 走向了为形式 而形式的极端主义。什么是艺术? 艺术是思想性、意境、主题和形式的综合体现。它反映的 是艺术家内心的情感世界或当下的生活。周国桢教授强调用艺术来反映时代的重要性。他结 
合自己从文革时期至今创作的作品, 形象地向在座年轻人诠释艺术家有责任通过造型艺术反 映这个时代。每个人都是时代的记录者, 只有表现了今天，才更有价值留给明天，让下一辈 通过这些艺术形象，了解过去并更好的展望未来。

纵观这场展览中的作品，陈硕的《椅子》、金文伟的《祥云飘过》、万里雅的《无题》 系列，乍一看均是人们熟悉的日常之物——椅子、高山、头像。但是在花瓣中用铜丝串联编 织的瓷片椅子却于中间突兀地乍现一条裂缝、山的外形之下云于顶峰飘过、头像上布满各种 关于城市、名作、娱乐的小方块集合, 这些均吸引着观者驻足观看, 静心思考作者于作品之 后想表达何种深意：是对现代生活的嘲讽? 是对隐居生活的向往? 还是对生活大爆炸式的反 思？结合他们的个人经历，不难发现，当熟练掌握陶艺传统制作工序之后，三位陶艺家不约 而同地开始将自己的关注点由外转内, 开始观照自己的内心情感及当下所处的生活, 对自身 和这个时代进行反思, 而展出的作品正是他们超脱技法, 开始对自己和社会予以关注的真实 写照。

此外，女陶艺家金贞华的最新力作《方向》系列延续她一直以来偏爱的具有空灵美感和 质感的白瓷, 用泥土通过与手的触摸捏制出片状的转折, 意欲表现当下物质充斥的社会中各 种可变不可控的方向。这些转折像折纸一样, 折来折去寻找着不同方向延展的可能性, 试图 以此不断探索白瓷成型的极限。同时这位女陶艺家也致力于关注大自然, 譬如大自然中微小 的孔洞元素，联想到气流流通和生命在夹缝中挣扎的现象。

艺术源于生活又高于生活，正是这种对于身边生活琐事的观照、思考和艺术升华，使得 陶艺家们更加明确面对传统和现代时, 应如何处理两者之间的关系, 即用现代的语言, 表达 中国人的情感和中国人的生活状态。

在周国桢教授呼吁年轻陶艺家应冷静看待中西方文化, 立足现实, 紧跟时代, 学人之长 并扬己之长时, 中国陶艺的国际话语权问题也随之成为了整场研讨会的另一个讨论焦点。景 德镇陶瓷大学金文伟教授分享了一段他自己的个人经历。2014年，作为唯一一位受聘于韩国 京畿道双年展, 协助当时的策展人办展的中国艺术家, 他发现尽管中国是所有参赛国家中人 数最多的国家, 但是该双年展却未设立一位中国评委。面对世界级的展览, 他终于意识到了 何为话语权, 何为文化自信。他认为作为陶瓷大国, 我们却在世界上没有什么话语权, 这种 现象的出现虽和语言这一客观因素有关，但究其根本还是我们艺术家自己本身的问题一一其 作品形态和在参展方面做的还不够到位。

然而上述的局面并非一成不变，正如开幕式上IAC中国区理事周光真先生介绍的，随着 更多中国陶艺家申请加入IAC, 十几年间他们借助这个国际平台出国参展、参与交流，同时 许多高校、社团机构邀请国际陶艺家来中国创作、参展、参与各种学术交流活动, 此外, IAC 还直接参与支持了许多国内的多项大型国际活动。随着我们与国际交流的日益增多, 当代陶 艺家们纷纷意识到，现在正是我们中国陶瓷艺术发声、获得话语权的时候。

但是这里所谓的发声, 并非是一种霸权, 而是一种平等对话, 即我们需要一个平等对话 的机会, 这种对话是一种开放式、平等式双向对话, 不是为了确定自身的立场, 一方说服另 一方的殖民主义，而是如同交响乐般每个声部共同发声时所演奏的和谐乐章。中国艺术研究 院艺术人类学研究所所长方李莉以理论旁观者的角度说道: “不卑不六, 平等对话是我们最 重要的态度。”这也就是在强调我们与世界对话时的态度, 我们不应该妄自菲薄, 也不应该 像以往那般妄自尊大, 将中国陶艺的发展又一次推向自言自语的困境。她认为, 文化是多样 性发展的, 并且东西方文化从来是你中有我、我中有你。她以西方现代陶艺为例, 阐述了当 代陶艺实际上是欧洲现代艺术到了美国, 同时东方禅宗也进入美国这片土地, 两者相融, 才 造就了当代陶艺这一后现代性艺术现象。因此当代陶艺的兴起与东方文化也是息息相关的。

“传统如何在现代化中重构” 成为继 “什么是属于我们中国的现代陶艺？”之后，陶艺 界专家学者需要反思的另一个问题。研讨会上, 多位艺术家结合自己的创作经历均不约而同 提到了两个词一一创新、原创。须知当艺术创作开始脱离自己的文化根源且缺乏自己个性化 
表达时, 自训为在传统底蕴下创新的艺术创作也就失去了存在价值, 至于如何在现代中转型 的问题, 更是无从谈起。作为老一代陶艺家, 姚永康教授和周国桢教授以身作则, 从风雨中 汲取营养，用自己个性化的语言践行着传统文化在现代中的转型。他们的作品结合中国文化 自己的特点和长处，很好地诠释了什么是中国艺术的价值核心，即在似与不似之间，能够似 于不似, 以一当十, 以十当百。与此同时，他们的作品还通过个性化的艺术手法反映了他们 所处每个时代节点的特征，使其艺术在传承中国传统文化的基础上，表现形式和主题思想都 与时俱进。

与此同时，紫砂壶陶艺家吴鸣也表示他在做紫砂的时候会特别强调传统，其中也会加入 自己的探索，但加入这些个性化的东西均以符合紫砂发展需要为前提。这些理念均可从其展 品《2013年的作品齐眉之五》中得知一二。这一系列作品保持紫砂的本体语言特征, 未施釉 的光滑表面给人细淢朴素之感。但是器形却已完全打破了紫砂与壶的对等号, 遵循对称法的 同时整体变形，使其与中国美好祝愿 “举案齐眉” 相呼应，让观者浮想联翩。一直以来，他 努力通过自己的作品向世人传达这样的信息: “从文化本质上来讲, 我们不应该完全遵循西 方的条例, 我们应该与自己的内心、文化、生活方式、哲学发生关系, 从而把自己的艺术推 向新的舞台和高度。”而拥有多年西班牙陶艺求学经历的台湾陶艺家谢嘉亨先生, 也表示在 他回台湾后一直致力于 “怎样融合两国间文化” 的思考。他认为器形代表一个国家和民族的 语言, 他尝试从中国传统陶瓷器型这个角度, 并施以西班牙闪光釉的方式来创作。通过两国 器形和釉料差异的对比, 不仅丰富了中国现当代陶艺的艺术表现形式, 而且对文化多样性和 文化融合方面的探索做出了巨大贡献。

此外，以拍摄陶艺题材的纪录片为主的女陶艺家谭红宇，用时下热门的新媒体媒介，传 达了她所认知的传统于现代化中的重构。她通过极具观赏性的拍摄手法和角度, 用摄像机去 记录那些努力实现传统与现代对话的艺术家们，比如她的纪录片作品《师傅》和《金砖》， 就分别记录了由传统向现代转型的石湾陶艺家曾鹏、曾力两兄弟, 和在二十一世纪科技发达 背景下仍然坚持传统工艺烧制故宫用砖的工匠们。这种用影像来记录传统文化的行为，是另 一种传统走向现代化的展现方式，且为后人提供了一份珍贵的文献资料。

整个研讨会现场，不仅IAC中国个人会员表达了他们的创作理念发展历程和对当今中国 陶艺的诸多思考, 团体会员们也向大家展示了他们自入会以来, 为将中国陶艺推向世界所作 出的努力。比如中央美术学院陶艺工作室, 作为国内美术高校, 在教学上坚持对学生进行严 谨的写实造型训练, 在强调立足中国传统的情况下, 引导他们了解和实践陶瓷材料的运用, 着力探索具有当代意义的陶瓷材料的语言特质, 拓展雕塑形态的材料表现领域。这是对于中 国传统文化与陶瓷本体材料、当代文化与个人感受、西方艺术经验与中国现状有机结合的有 益尝试。同时他们很注重国际交流方面的工作，不仅邀请国外艺术家来校指导，也会主动走 出国门与他人交流。这些均是对他们理念 “回望传统、关注当下、展望未来” 的完美阐释。

除了国内艺术高校，企业机构自成立并加入IAC之后，也积极担负自己的社会文化责任， 为中国陶艺做出贡献。譬如国内首家以陶艺为主题, 集国际陶文化交流、科研教学、生态观 光、休闲旅游、国际陶艺展览为一体的国际陶文化交流企业一一富平国际陶艺村。通过该陶 艺村代表严小强先生的介绍, 我们了解到富平国际陶艺村一直致力于开展国际陶艺创作交流 活动, 且每三年举办一次国际陶艺杂志主编论坛, 进行许多陶艺方面的学术探讨, 同时还举 办国际陶艺新秀作品竞赛。这些均已被国际陶艺届人士视为一种 “中国富平”现象。对于推 动和引领当代世界陶艺文化的发展, 它的重要性和影响力与日俱增。由此也让我们对中国陶 艺未来于世界逐渐攀升的地位更具信心。

\section{4. 结束语}

《士别三日一一IAC中国会员作品与文献巡回展》是一次IAC中国成员的自身总结，不同 于以往的陶艺展, 展厅的作品与随后的研讨会相辅相成, 发生着一加一大于二的化学反应。 
通过展品我们直面中国当代陶艺的百花齐放：既有坚持中国传统符号元素的雕塑、又有传统 器形与抽象元素相结合的纯观念艺术、更有当下时兴的装置艺术, 展出的国内外陶艺杂志、 陶艺专著、展览画册等更是供观众翻阅, 令其感受最前沿的国内外当代陶艺资讯。研讨会则 深度剖析展品背后的深意, 通过时间线索, 以幻灯片为媒介让观众感受艺术家们一路走来的 创作历程和人生感悟。时间与空间的穿越、横向与纵向的交错, 这场展览向观众娓娓道来: 自IAC中国个人及团体会员加入这一国际陶瓷协会的十余年间, 通过全体会员努力将中国的 陶瓷文化带向世界、传播中国传统文化并争取更多中国文化国际话语权, 中国当代陶艺在国 际上的影响力早已今非昔比。当然, 这场展览的圆满成功更是他们下一次征程的起点。它不 仅是IAC在中国首次以会员展览的形式亮相，还是展现中国当代陶瓷文化鬼米力的暖身活动。

作为千年瓷都, 景德镇被选为这次巡回展的第一站, 其背后深具历史意义。景德镇早在 宋代, 其生产的陶瓷已与世界开始交流, 作为文化传播的有效媒介, 承载着中国的文化和制 造技术, 走向世界。景德镇作为一个 “工匠八方来, 器成天下走” 的城市, 曾是世界陶瓷的 中心。虽然一度没落, 但是随着中国当代陶艺家在国际上的活跃表现, 景德镇又再度成为了 世界陶瓷的中心。这时的景德镇已然是一座 “艺术家八方来” 的城市, 每年上万的景漂一族 滋养着这片土地, 各地不同的文化在这里激烈碰撞。景德镇是陶瓷文化的原点, 它承载着诸 多陶艺家对于瓷的追求, 而 $\mathrm{IAC}$ 是桥梁, 连接着中国与世界, 让中国文化继海上丝绸之路之 后, 再次扬帆起航一二二十一世纪, 当代陶艺从景德镇出发, 走向全国, 走向世界。

\section{致谢}

本文为国家社科基金艺术学一般项目《中国古代陶瓷批评史研究》(16BF079)的阶段性成 果之一。

\section{References}

[1] Zhang Ganlin, Chinese Ceramic Art Criticism, Hebei Fine Arts Publishing House, pp. 107-111, 2013. 